\title{
Mortality Observed in the General Surgery Department " $A$ " at the University Hospital Center of Point " $G$ " in Bamako
}

\author{
Sidiki Keita1 ${ }^{*}$, Koniba Keita ${ }^{2}$, Moussa Sissoko', Mahamadou Coulibaly ${ }^{1}$, Lamine Soumare1, \\ Oumar Sacko ${ }^{1}$, Oulématou Coulibaly ${ }^{3}$, Sekou Koumaré ${ }^{1}$, Adama Keita ${ }^{1}$, Adama K. Koita1, \\ Soumaîla Keita1, Zimogo Zié Sanogo ${ }^{1}$
}

${ }^{1}$ General Surgery “A” Department, Hospital Point-G, Bamako, Mali

${ }^{2}$ General Surgery Department, Hospital BSS, Kati, Mali

${ }^{3}$ Reference Health Center of Commune VI, Bamako, Mali

Email: *sidikibafing@yahoo.fr

How to cite this paper: Keita, S., Keita, K., Sissoko, M., Coulibaly, M., Soumare, L., Sacko, O., Coulibaly, O., Koumaré, S., Keita, A., Koita, A.K., Keita, S. and Sanogo, Z.Z. (2021) Mortality Observed in the General Surgery Department "A" at the University Hospital Center of Point "G" in Bamako. Surgical Science, 12, 119-126.

https://doi.org/10.4236/ss.2021.124014

Received: November 18, 2020

Accepted: April 20, 2021

Published: April 23, 2021

Copyright $\odot 2021$ by author(s) and Scientific Research Publishing Inc. This work is licensed under the Creative Commons Attribution International License (CC BY 4.0).

http://creativecommons.org/licenses/by/4.0/ (c) (i) Open Access

\begin{abstract}
In Mali, few studies have concerned overall mortality in general surgery, but several specific studies have concerned the different affections. Reflection on the causes of death is an inherent part of the activity of any motivated surgical team. Objective: To analyze the rate and the main causes of mortality in the General "A" surgical department of the Point "G" CHU. Patients Method: Our study was retrospective, descriptive and covered a period of 5 years from 01/01/2014 to 12/31/2018. We collected 152 deaths for 2011 hospitalized patients. The data were collected from the files of these deaths on pre-established investigation forms. The deceased patients were classified as operative and non-operative death, death from non-cancerous and cancerous diseases, deaths occurring in emergencies and deaths in regulated surgery. Results: We recorded 152 cases of death for 2011 hospitalized patients, either an overall mortality rate of $7.55 \%$. The average age of deaths was 44.20 years +-17.51 years with extremes ranging from 7 years to 85 years. The sex ratio was 1.62 in favor of men. The causes of death were represented by cancerous pathologies (69 deaths or $34.67 \%$ ), non-cancerous pathologies (83 deaths or $4.58 \%)$. Conclusion: The mortality rate in general surgery remains high and is mainly linked to cancerous pathologies and the delay in taking care of patients.
\end{abstract}

\section{Keywords}

Mortality, General Surgery, Cancer, Non-Operated, Operated 


\section{Introduction}

Reflection on the causes of death is an inherent part of the activity of any motivated surgical team [1]. The difficulties in establishing the causes of death are linked on the one hand to "poly pathology" and on the other hand to the difficulty of obtaining precise clinical data, to which must be added the incidents and accidents involving the patient care team, with a tendency to minimize or obscure them [2] [3]. Few studies have concerned overall mortality in general surgery, but several specific studies have concerned the different affections (peritonitis, appendicitis, hernias, digestive cancers, biliary and pancreatic pathologies, etc.). In Africa, hospital mortality studies are studies carried out in pediatric, gyneco-obstetrics, internal medicine and infectious diseases, but rarely in general surgery [4]. Screening campaigns for cancerous pathologies, delay in diagnosis, delay in taking charge of patients, insufficient budgetary resources allocated to health, poor distribution of personnel, especially specialized personnel, most of the specialists working in large cities, all these facts are factors which act negatively on the state of health of populations in general and on the state of health of patients hospitalized in a specialized environment in particular. We considered it necessary to take stock of mortality in the general surgery departments. This retrospective study makes it possible to evaluate the activity of the service by grouping together the probable causes of death, because to date the dissection of deceased patients is not required in our hospitals.

\section{The Objectives of Our Study}

\subsection{General Objective}

The general objective of this study is to identify the different causes of mortality in our service.

\subsection{Specific Objectives}

Highlight the overall death rate during the study, assess the real rate of deaths linked to surgical interventions, assess the frequency of cancer-related deaths, assess the frequency of deaths linked to patients undergoing emergency and cold surgery, study for each of the ailments in question the various factors linked to the patients, their disease and the medico-surgical environment. In light of the problems posed by deaths in a surgical department in Mali, determine the share that goes directly to the surgical act.

\section{Patients and Method}

This was a retrospective, descriptive, analytical study and focused on deaths that occurred in the " $A$ " surgical department of the Point " $G$ " university hospital in Bamako. The classification in operative and non-operative death, in death from non-cancerous and cancerous conditions, in emergency and cold deaths was intended to determine the causes of death. This study covered 5 years of service activity from 01/01/2014 to 12/31/2018. We collected 152 deaths for 2011 hospi- 
talized patients. The " $A$ " surgical department of the Point "G" $\mathrm{CHU}$ included two pavilions with 42 beds in total.

\subsection{Data Collection}

The collection of data in the medical files was done in ascending chronological order from $01 / 01 / 2014$ to $12 / 31 / 2018$, from hospitalization registers, medical files, and the HOSIX computer system. All the data has been established on an exploitation sheet. A complete file included a medical observation mentioning the demographic data, the a etiological circumstances, the clinical presentations, the results of the paraclinical examinations carried out, the surgical therapeutic attitude and the postoperative evolution on the date of the last follow-up. The study parameters were etiological, clinical, paraclinical, surgical therapy and short- and medium-term postoperative progression.

\subsection{Statistic Study}

For the statistical study, we plotted all the data on an Excel table and we used the SPSS 17.0 software. The qualitative variables of our study were expressed in percentage and in number, while the quantitative variables in means $+/$ - standard deviations. The results are reported in the form of graphs and commented tables.

\subsection{Inclusion Criteria}

All cases of operated or non-operated death occurring in our department, cases of abscesses operated on under general anesthesia were considered as not operated.

\subsection{Non-Inclusion Criteria}

Cases of death registered in another service even if the patient is operated on by our team, patients who left against medical advice.

\section{Results}

The crude death rate of operated and non-operated patients was 152 deaths, or $7.55 \%$ of cases. During the study period 2011 patients were hospitalized, among them around 1800 patients (90\% of cases) were operated on and 211 patients (10\% of cases) were not operated (Table 1). $63 / 152$ or $41.44 \%$ of the deaths were operative and $89 / 152$ or $58.56 \%$ of the deaths were non-operative. We recorded about 30 deaths per year, men were the most represented (94 deaths or $61.84 \%$ of cases) with a sex ratio of 1.62 in favor of men. The average age of deaths was 44.20 years \pm 17.51 years with extremes ranging from 7 to 85 years (Table 2). About $71 \%$ of the deaths occurred outside of working hours.

521 patients were admitted in emergency with 70 deaths or a rate of $13.43 \%$ of cases. Among them 84 non-operated patients including 37 deaths, either an emergency non-operative death rate of $44.04 \%$. 437 were operated on urgently with 33 deaths, either a mortality of $7.55 \%$ of cases. Of the 1490 cold admitted 
Table 1. Percentage of hospitalizations and patients operated on and not operated on by year.

\begin{tabular}{cccc}
\hline Year & $\begin{array}{c}\text { Total hospitalized } \\
\text { patients }\end{array}$ & $\begin{array}{c}\text { Number of operated } \\
\text { patients }\end{array}$ & $\begin{array}{c}\text { Number of } \\
\text { non-operated patients }\end{array}$ \\
\hline $\mathbf{2 0 1 4}$ & 393 & $339(85.5 \%)$ & $57(15.5 \%)$ \\
$\mathbf{2 0 1 5}$ & 314 & $295(93.95 \%)$ & $19(6.5 \%)$ \\
$\mathbf{2 0 1 6}$ & 423 & $369(87.23 \%)$ & $54(12.77 \%)$ \\
$\mathbf{2 0 1 7}$ & 434 & $379(87.33 \%)$ & $55(12.67 \%)$ \\
$\mathbf{2 0 1 8}$ & 447 & $421(94.18 \%)$ & $26(5.82 \%)$ \\
Total & 2011 & $1800(89.50 \%)$ & $211(10.50 \%)$ \\
\hline
\end{tabular}

Table 2. Distribution of deaths by age group.

\begin{tabular}{ccc}
\hline Age group & Number of deaths & Percentage \\
\hline Under 20 & 8 & 5.26 \\
$\mathbf{2 0}-\mathbf{3 9}$ years & 43 & 28.28 \\
$\mathbf{4 0}-\mathbf{5 9}$ years & 59 & 38.81 \\
$\mathbf{6 0}-\mathbf{7 9}$ years & 40 & 26.31 \\
$\mathbf{8 0}$ years and over & 2 & 1.31 \\
Total & $\mathbf{1 5 2}$ & $\mathbf{1 0 0}$ \\
\hline
\end{tabular}

patients, we deplored 82 cases of death, either a mortality of 5.50\%, among them 127 non-operated patients with 52 deaths or an operative mortality of $40.94 \%$ and 1363 patients operated on with 30 deaths or a cold operative mortality of $2.20 \%$.

1812 patients were hospitalized for non-cancerous conditions in which we recorded 83 deaths or $4.58 \%$ of cases. Among them 49/153 non-operative deaths, either $32.02 \%$ of cases or 1659 patients having been operated on, we recorded 34 deaths, either a mortality rate of $2.05 \%$ of cases. The non-cancerous and unoperated conditions (Table 3) causing the deaths were: occlusive syndrome (small intestine, colon) 13 cases or $26.53 \%$ of cases; thermal burns greater than $30 \%$ of body surface 5 cases, either $10.20 \%$; arteriopathy obliterating of the lower limbs 4 cases or $8.16 \%$; abscesses and bedsores 6 cases or $12.25 \%$. The specific death rates of non-cancerous patients operated (Table 4) on were: peritonitis (68 cases, 7 deaths, either a mortality rate of $10.29 \%$ ); intestinal obstructions (87 cases including 14 deaths, or $16.09 \%$ mortality rate); penetrating wounds of the abdomen and/or thorax (21 cases, 2 deaths, either a mortality rate of $9.52 \%$ ); uterine fibroids (89 cases, 1 death or 1.12\%); the other causes of death were: lung cyst (1 case); mesentery infarction (1 case); pericarditis (1 case); postoperative eventration ( 1 case); and a case of hernia having lost the right to cite.

We hospitalized 199 cancer patients, 69 of whom died, for a mortality rate of $34.67 \%$. Among them 58 unoperated patients including 40 deaths (Table 5), a mortality rate of $68.96 \%$; 141 patients operated on, 29 of whom died, for a mortality rate of $20.57 \%$ (Table 6). Among the cancers operated on, we had 67 cases 
Table 3. Conditions causing non-cancerous and unoperated deaths.

\begin{tabular}{ccc}
\hline Conditions & Number of deaths & Percentage \\
\hline Chronic infectious lung disease & 7 & 14.29 \\
Occlusive syndrome (small intestine-colon) & 13 & 26.53 \\
Post abortal pelvi-peritonitis & 2 & 4.08 \\
Thermal burn > 30\% & 5 & 10.20 \\
Polytrauma & 2 & 4.08 \\
Gangrene & 4 & 8.16 \\
Abscesses and bedsores & 6 & 12.25 \\
Snake bite & 1 & 2.04 \\
Pyloric stenosis & 2 & 4.08 \\
Gastrointestinal bleeding & 1 & 2.04 \\
Causes not determined & 6 & 12.25 \\
Total & 49 & 100 \\
\hline
\end{tabular}

Table 4. Death rate of non-cancerous patients operated.

\begin{tabular}{cccc}
\hline Affections & $\begin{array}{c}\text { Number of patients } \\
\text { operated }\end{array}$ & $\begin{array}{c}\text { Number of deceased } \\
\text { patients }\end{array}$ & Percentage \\
\hline $\begin{array}{c}\text { Digestive surgery } \\
\text { (appendicitis excluded) }\end{array}$ & 301 & 25 & 8.30 \\
Gynecological surgery & 346 & 1 & 0.29 \\
Urologic surgery & 98 & 2 & 2.04 \\
Thoracic surgery & 72 & 4 & 5.55 \\
Other surgeries & 847 & 2 & 0.23 \\
Total & 1659 & 34 & 2.04 \\
\hline
\end{tabular}

Amputation, thyroidectomy, varicose veins, appendectomy, wall surgery.

Table 5. Deaths of unoperated cancer patients.

\begin{tabular}{ccc}
\hline Cancers & Effectif & Percentage \\
\hline Digestive & 29 & 72.50 \\
Bladder & 4 & 10 \\
Uterus & 4 & 10 \\
Breast & 3 & 7.50 \\
Total & 40 & 100 \\
\hline
\end{tabular}

Table 6. Deaths of cancer patients operated.

\begin{tabular}{cccc}
\hline Cancers & \multirow{2}{*}{$\begin{array}{c}\text { Number of } \\
\text { operated patients }\end{array}$} & Number of patients & Percentage \\
\cline { 3 - 4 } Digestive & 102 & 23 & 22.55 \\
Gynecological & 26 & 3 & 11.54 \\
\hline
\end{tabular}


Continued

\begin{tabular}{cccc}
\hline Urological & 6 & 2 & 33.33 \\
Pulmonary & 2 & 0 & 0 \\
Other & 5 & 1 & 20 \\
Total & 141 & 29 & 20.56 \\
\hline
\end{tabular}

of stomach cancer with 16 deaths, or $23.88 \%$; colon cancers $(5 / 20$ deaths or $25 \%$ of cases); mesentery cancers (8 cases operated on and with death); cancer of the esophagus ( 5 operated cases, 3 deaths or 60\%); uterine cancer (13 cases, 2 deaths, or $15.98 \%$ ); breast cancer (3 cases, one of which died, either $7.69 \%$ ); thyroid cancer ( 3 cases including one death, either $33.33 \%$ ); bladder cancer (4 cases including one death).

The death rate observed by group of disease was 99/493 digestive disorders or $20.08 \%$ of cases, $11 / 374$ gynecological disorders or $2.94 \%$ of cases, $7 / 109$ urological disorders or $6.42 \%$ of cases, $9 / 107$ thoracic affections or $8.41 \%$ of cases. Note that simple appendicitis did not record any death.

\section{Discussion}

Our study was a retrospective, descriptive, analytical and focused on the deaths which occurred in the surgical department " $A$ " of the university hospital of Point "G" of Bamako, during a period of 5 years from 01/01/2014 to 31/12/2018.

The mean age of the deceased patients was $44.20 \pm 17.51$ years. The extremes were from 7 years to 85 years, $40 \%$ of the deaths are between 40 and 59 years. The sex ration of 1.62 was in favor of men. TAKONGMO S [5] in Cameroon had found 208 cases of death occurring in subjects aged 8 to 85 years, of which 129 were men or $62 \%$ and 79 women or 38\%. Proye in France [1] in 1990 found an average age of deceased patients of 63.7 years with extremes of 39 to 95 years; $34.5 \%$ were $\geq 70$ years old. The death curve by year and by sex found about 30 deaths per year and a sex ratio of 1.62 in favor of men.

On 2011 hospitalized patients, we recorded 1800 surgical interventions, i.e. a frequency of $89.50 \%$. 211 hospitalized patients did not undergo surgery or $10.50 \%$. We collected 152 deaths, for an overall mortality rate of 7.55\%. Among the 1800 patients operated on, 63 patients died, i.e. 3.5\% mortality. We recorded 33 emergency operative deaths, the occlusions represented 16 cases $(48.48 \%)$; peritonitis 7 cases $(21.21 \%)$; traumatic wounds 2 cases $(6.06 \%)$; occlusions in cancer 5 cases $(15.15 \%)$; 1 case of perforation in stomach cancer; 1 case of mesentery infarction and 1 purulent pericarditis. The particularity of emergency interventions has been highlighted in several studies [1] [5]. According to CORIAT [6] when the intervention is carried out in emergency, the general repercussion of the digestive affection which imposes the surgery, the ignorance of certain defects presented by the operated, the possibility of regurgitation, even the inhalation of gastric liquid in patients operated on who are not fasting or who are in digestive obstruction, represent as many additional risk factors. We 
deplored 89 deaths for 211 unoperated patients. It should be noted that among the cases of non-operative death, there were 49 cases of death from non-cancerous conditions, including 13 cases of occlusion; 2 cases of pyloric stenosis; 2 cases for trauma; 2 cases of pelviperitonitis; 5 cases of thermal burns; 1 case of snake bite; 4 cases of arterial disease obliterating the lower limbs; 1 case of hemorrhagic diarrhea; in 6 cases we were unable to justify the cause of death. 40 cases of death from cancerous diseases among which: 16 cases died from cancer; in 24 cases of death the diagnosis of cancer exceeded for surgery was made. Among the cancerous patients not operated (58 cases) we had recorded 40 deaths, 16/40 deaths for cancer, either $40 \%$ had undergone a previous surgical intervention. These 16 cases were re-hospitalized in the terminal phase of their cancer. 24/40 cancer deaths or $60 \%$ have never been operated on. Different authors have insisted on "surgical abstentions" without alluding to "non-operative mortality" in their department [2] [3] [7]. Postoperative mortality from cancerous diseases was 29 cases of death out of 141 patients, either $20.56 \%$. Among these deaths, 24 concerned digestive surgery (16/67 stomach cancers, 5/20 colonic cancers and 3/5 esophageal cancers) and 5 deaths concerned other cancers operated on $(2 / 13$ deaths), cancer of the uterus (1/13 death), breast cancer (1/3 death), bladder cancer ( $1 / 3$ death).Our relatively high postoperative mortality rate was mainly due to the late diagnosis of these tumors admitted to the department. Outdated cancers diagnosed at the first surgical consultation are rare in Europe because of the early detection of cancers [8] [9]. Screening as organized in Japan has treated superficial stage cancers in more than $35 \%$ of cases [10]. In Mali, the delay in diagnosis by the insufficiency of medico-sanitary infrastructure, the cult maintained of the effectiveness of traditional medicine, mean that we receive tumors at outdated stages for surgery although in the service we try the maximum palliative actions whenever there is a possibility of relieving the patient.

\section{Conclusion}

We estimated necessary to do the point on mortality in a general surgery department. This descriptive and retrospective study made it possible to assess the activity of the service by grouping together the probable causes of death, because to date the dissection of deceased patients is not required in our hospitals. The late recourse to medical care, the lack of systematic cancer screening, insufficient technical facilities, the financial problems of patients, have contributed to the rise in the rate of hospital deaths in the department. This high mortality rate can be lowered by acting on three parameters: by lowering the emergency mortality rate; by creating an oncology service; by strengthening the surgical, anesthesia and resuscitation teams.

\section{Limitations of the Study}

It was a retrospective study. The main difficulty was incomplete files due to the lack of an archiving service. We have lost sight of many of our patients. None of 
our bodies have undergone an autopsy for lack of a forensic pathologist.

\section{Conflicts of Interest}

The authors declare no conflicts of interest regarding the publication of this paper.

\section{References}

[1] Proye, C., Martinot, I.C., Triboulet, J.P., Varnaille, B., Sautier, M., Dromer, D. and Camp, D. (1991) Mortalité d'un service de chirurgie générale de CHU. Journal de Chirurgie (Paris), 11, 453-458.

[2] James, G., Patton, R.E. and Heslin, A.S. (1955) Accuracy of Cause-of-Death Statements on Death Certificates. Public Health Reports, 70, 39-59.

[3] Justin Besanson, L., Delaviei, R.P. and Chretien, J.L. (1963) Recherche des causes de mortalité à l'aide de 1000 confrontations anatomo-cliniques. Bulletin de la Société de Médecine de Paris, 114, 815-824.

[4] Dékou, A., Ouergnin, G.A., Konan, P.G., Kouamé, B., Fofana, A., Kramo, N., Konin, A., Manzan, K.and Djédjé, M.A. (2009) Contribution à l'étude de la mortalité dans un service d'urologie: Le cas du service d'urologie du CHU de Cocody d'Abidjan de 2000 à 2006. African Journal of Urology, 15, 44-52. https://doi.org/10.1007/s12301-009-0009-4

[5] Takongmo, S., Angwafof, F., Binam, F., Afane Ela, A., Fonkou, A., Gaggini, J., Le Saint, B., Lantum, D. and Malonga, E. (1993) Mortalité hospitalière en milieu chirurgical: nécessité de l'audit médical. Médecine d Afrique Noire, 40, No. 12.

[6] Coriat, P., Collard, D., Villet, R. and Mourot, J. (2012) Evaluation du risque opératoire en chirurgie digestive. EMC, (Paris), Techniques chirurgicales Appareil digestif, 40010, 4-8-12.

[7] Hollender, L.F., Kauffmann, J.P. and Bur, F. (1983) Etude rétrospective de 384 exérèses pour cancers gastriques. Journal de Chirurgie, 109, 731-741.

[8] Sirgon, R., Canzoniri, V., Cannizao, R. and Pasquoti, B. (1998) Early Gastric Cancer: Diagnostic Surgical. Treatment and Follow-Up of 45 Cases. Tumori, 84, 547-551. https://doi.org/10.1177/030089169808400507

[9] De Manzoni, G., Di Leo, A., Borzellino, G., Pedrzzani, C., Tasseli, S., Castelli, A., Zerman, G. and Fersini, A. (2001) Envahissement des ganglions para-aortiques dans les adénocarcinomes de l'estomac. Annales de Chirurgie, 126, 302-307. https://doi.org/10.1016/S0003-3944(01)00521-1

[10] Segol, P.H., Vermaerde, J.C., Fournier, J.L., Chomon-Towski, J. and Salame, E. (1994) Cancer de l'estomac notions fondamentales et diagnostics. Edition tech, EMC, 9-027 A1O, $18 \mathrm{p}$. 